\title{
Incidence of asthma in Swedish teenagers: relation to sex and smoking habits
}

\author{
Lars Larsson
}

\begin{abstract}
Background - The prevalence of asthma and the use of asthma drugs is increasing worldwide. Studies of the incidence of asthma are few but are of interest in finding factors associated with onset of the disease. A study was performed to estimate the incidence of asthma and its relation to sex and to tobacco smoking between the ages of 16 and 19 years, and to compare the incidence of asthma with the proportion of individuals receiving a prescription of an asthma drug for the first time during one year.

Methods - A questionnaire was sent in 1990 to all 3627 individuals born in 1974 living in the county of Jämtland and Gästrikland, the southern part of the county of Gävleborg in central Sweden. Individuals reporting airways disease or obstructive symptoms were investigated with a further interview and lung function tests. The cross sectional questionnaire study was repeated in 1993. The incidence of asthma was calculated in the 2308 individuals who answered the questionnaire in both surveys and who were found not to have asthma in 1990.
\end{abstract}

Results - The yearly incidence of asthma defined from self reported disease, physician diagnosed asthma, drug use, or asthma associated symptoms was between $0.8 \%$ and $1.3 \%$, depending on the criteria used. All criteria used resulted in a higher incidence in female subjects. Female sex was a risk factor for asthma when standardised for smoking, and smoking was also a risk factor for asthma when standardised for sex to all but two of the criteria used. In all the criteria the increased risk of asthma combined with smoking was greater in female subjects.

Department of Pulmonary Medicine, Östersund Hospital, Ostersund and National Institute of Occupational Health, Medical Division, Umeå, Sweden L Larsson

Reprint requests to: Dr Lars Larsson Department of Pulmonary Medicine, Östersund Hospital, S-831 83 Östersund, Sweden

Received 18 July 1994 Returned to authors Returned to auth Revised version received Revised version receiv Accepted for publication 24 November 1994
Conclusion - The yearly incidence of asthma was about $1 \%$ between the ages of 16 and 19 years. Smoking and female sex were found to be risk factors for asthma. The incidence of asthma was close to the incidence of new drug use for asthma. (Thorax 1995;50:260-264)

Keywords: asthma, epidemiology, age, sex, smoking.

The prevalence of asthma has been reported to be increasing in many countries, ${ }^{1}$ but these studies are of limited value in finding factors associated with the development of the disease. Studies of incidence (proportion of the previously healthy population contracting the dis- ease over a defined time) have the advantage that the observed exposure is closer in time to the onset of the disease. Few studies of the incidence of asthma have been reported. In the USA a total yearly incidence of $0.4 \%$ was found from birth to old age, with the lowest levels occurring in late adolescence. ${ }^{2}$ Considerably higher levels have been reported from the UK $-0.56 \%$ in men and $0.94 \%$ in women aged between 17 and 23 years - and a strong association was found with the presence of atopic disease at the time of onset of asthma. ${ }^{3}$ This correlation did not explain the considerable sex difference found, however, and smoking habits were not reported.

Sales of asthma drugs vary considerably between counties in Sweden. We have reported the prevalence of airways symptoms ${ }^{4}$ and of obstructive airways disease $e^{5}$ in the counties of Jämtland (where the use of asthma drugs is high) and Gävleborg (where it is lower) and found a higher cumulative prevalence of asthma, as well as prevalence of current asthma, in the less industrialised and urbanised but colder county of Jämtland.

The incidence of the use of medication - that is, the proportion of the population receiving a prescription for a drug for the first time - is continuously recorded in the county of Jämtland. The "medication incidence" of asthma drugs (group R03 in Anatomical Therapeutic Chemical (ATC) classification system) in individuals aged $10-19$ years was $1 \cdot 3 \%(1 \cdot 4 \%$ females, $1 \cdot 1 \%$ males $)$ in $1990,1 \cdot 1 \%(1.3 \%$ versus $0.8 \%)$ in 1991 , and $1.5 \%(1.9 \%$ versus $1 \cdot 2 \%)$ in $1992 .^{6}$ There are no reports of the incidence of asthma in Sweden.

In 1990 a postal questionnaire was sent to all individuals born in 1974 living in the county of Jämtland and Gästrikland, the southern part of the county of Gävleborg. Symptomatic individuals were interviewed and examined and asthma was diagnosed in individuals reporting a typical history of asthma, or symptoms of asthma and reversibility of forced expiratory volume in one second $\left(\mathrm{FEV}_{1}\right)$, peak expiratory flow (PEF) variability, or bronchial hyperresponsiveness. To study the incidence of asthma and the correlation between the incidence of new drug use for asthma and the incidence of the disease the postal questionnaire was distributed to the same population a second time in 1993.

\section{Methods}

A 22 item postal questionnaire was distributed in February 1990 to all 3627 individuals born 
in 1974 in the county of Jämtland and in Gästrikland. The questionnaire was answered by 3308 individuals (91\%) after two reminders. The study population has been described elsewhere. ${ }^{4}$ All individuals reporting a respiratory disease that was previously known, use of asthma medication, or symptoms indicating possible obstructive airways disease $(n=554)$ and a random sample of individuals not reporting any of these $(n=193)$ were invited to a further examination and 594 individuals agreed. The selection and the methods used have been described in detail elsewhere. ${ }^{5}$

In February 1993 the questionnaire was once again sent to the same study population. Of the original 3627 individuals 3303 were still resident in the study area and, of these, 2734 responded. In total 2579 individuals $(71 \%$ of the initial cohort and $78 \%$ of those still resident in the area) participated in both surveys. Those reporting they had ever had asthma or that they had asthma diagnosed by a physician in 1990 ( $\mathrm{n}=166)$ were excluded. In addition, 61 individuals who did not report asthma but who were found to have the disease at the examination, and 44 individuals who reported asthma associated symptoms in 1990 but did not take part in the examination, were excluded. The remaining 2308 individuals (1188 males and 1120 females) were considered not to have had asthma in 1990. The incidence of asthma was calculated by the proportion of this group giving positive answers to questions on diagnosis, symptoms, and medication in 1993.

Those reporting that they were smokers in either of the questionnaires in 1990 or 1993 , and those reporting that they had never smoked in 1990 and who stated that they were ex- smokers in 1993, were regarded as having been smokers during the observation period.

Of the 2308 individuals included in this study 117 were investigated (with interview, lung function tests, allergy tests and PEF recordings) as controls in the second part of the initial survey.

The study was approved by the ethics committee at the University of Umeå.

\section{DATA ANALYSIS}

Differences in the incidence between groups were tested for statistical significance using the $\chi^{2}$ test, two tailed $\mathrm{p}$ value.

\section{Results}

The yearly incidence of symptoms was $2 \cdot 7 \%$ for shortness of breath and $1 \cdot 7 \%$ for frequent wheezing. The yearly incidence of asthma, calculated as the proportion of the population reporting that they had asthma or physician diagnosed asthma, was $1 \cdot 2 \%$ and $1 \cdot 1 \%$ (table 1). The use of a combination of diagnosed disease and current use of asthma medication gave an incidence of $0.8 \%$. The corresponding figure for attacks of shortness of breath and current use of asthma medication was $1 \cdot 2 \%$. The combination of frequent wheezing and attacks of shortness of breath resulted in the highest incidence $(1 \cdot 3 \%)$, while frequent wheezing and current drug use resulted in the lowest incidence $(0 \cdot 8 \%)$. In all definitions the incidence was significantly higher in female than in male subjects (table 1).

The proportion of smokers and ex-smokers was three times higher in 1993 than in 1990 .

Table 1 Number of individuals and percentage of population with three year incidence of asthma and corresponding yearly incidence

\begin{tabular}{|c|c|c|c|c|}
\hline Question & $n$ & $\%(95 \% C I)$ & $p($ male $v$ female $)$ & \%/year \\
\hline $\begin{array}{l}\text { Attacks of shortness of breath? } \\
\text { Males } \\
\text { Females }\end{array}$ & $\begin{array}{r}186 \\
74 \\
112\end{array}$ & $\begin{array}{l}8 \cdot 1(7 \cdot 0 \text { to } 9 \cdot 2) \\
6 \cdot 2(4 \cdot 8 \text { to } 7 \cdot 6) \\
10 \cdot 0(8 \cdot 2 \text { to } 11 \cdot 8)\end{array}$ & $<0.005$ & $\begin{array}{l}2 \cdot 7 \\
2 \cdot 1 \\
3 \cdot 3\end{array}$ \\
\hline $\begin{array}{l}\text { Do you usually have wheeze in the chest? } \\
\text { Males } \\
\text { Females }\end{array}$ & $\begin{array}{r}116 \\
52 \\
64\end{array}$ & $\begin{array}{l}5 \cdot 0(4 \cdot 1 \text { to } 5 \cdot 9) \\
4 \cdot 4(3 \cdot 2 \text { to } 5 \cdot 6) \\
5 \cdot 7(4 \cdot 3 \text { to } 7 \cdot 1)\end{array}$ & $0 \cdot 17$ & $\begin{array}{l}1.7 \\
1.5 \\
1.9\end{array}$ \\
\hline $\begin{array}{l}\text { Have you ever had asthma? } \\
\text { Males } \\
\text { Females }\end{array}$ & $\begin{array}{l}85 \\
33 \\
52\end{array}$ & $\begin{array}{l}3.8(3.0 \text { to } 4.6) \\
2.9(1.9 \text { to } 3.9) \\
4.8(3.6 \text { to } 6.0)\end{array}$ & 0.02 & $\begin{array}{l}1.2 \\
0.9 \\
1.5\end{array}$ \\
\hline $\begin{array}{l}\text { Asthma diagnosed by physician? } \\
\text { Males } \\
\text { Females }\end{array}$ & $\begin{array}{l}74 \\
28 \\
46\end{array}$ & $\begin{array}{l}3 \cdot 2(2 \cdot 5 \text { to } 3 \cdot 9) \\
2 \cdot 4(1.5 \text { to } 3 \cdot 3) \\
4 \cdot 1(2 \cdot 9 \text { to } 5 \cdot 3)\end{array}$ & 0.02 & $\begin{array}{l}1 \cdot 1 \\
0 \cdot 8 \\
1 \cdot 4\end{array}$ \\
\hline $\begin{array}{l}\text { Current use of asthma drgus? } \\
\text { Males } \\
\text { Females }\end{array}$ & $\begin{array}{l}93 \\
32 \\
61\end{array}$ & $\begin{array}{l}4 \cdot 0(3 \cdot 2 \text { to } 4 \cdot 8) \\
2 \cdot 7(1.8 \text { to } 3 \cdot 6) \\
5 \cdot 5(4 \cdot 2 \text { to } 6 \cdot 8)\end{array}$ & $<0.005$ & $\begin{array}{l}1.3 \\
0.9 \\
1.8\end{array}$ \\
\hline $\begin{array}{l}\text { Asthma diagnosed by physician and } \\
\text { current use of asthma drugs? } \\
\text { Males } \\
\text { Females }\end{array}$ & $\begin{array}{l}59 \\
19 \\
40\end{array}$ & $\begin{array}{l}2 \cdot 6(2 \cdot 0 \text { to } 3 \cdot 3) \\
1.6(0 \cdot 9 \text { to } 2 \cdot 3) \\
3 \cdot 7(2 \cdot 6 \text { to } 4 \cdot 8)\end{array}$ & 0.005 & $\begin{array}{l}0 \cdot 8 \\
0 \cdot 5 \\
1 \cdot 2\end{array}$ \\
\hline $\begin{array}{l}\text { Attacks of shortness of breath and current } \\
\text { use of asthma drugs? } \\
\text { Males } \\
\text { Females }\end{array}$ & $\begin{array}{l}86 \\
30 \\
56\end{array}$ & $\begin{array}{l}3.7(2.9 \text { to } 4.5) \\
2.5(1.6 \text { to } 3.4) \\
5.0(3.7 \text { to } 6.3)\end{array}$ & $<0.005$ & $\begin{array}{l}1 \cdot 2 \\
0.9 \\
1.7\end{array}$ \\
\hline $\begin{array}{l}\text { Usually have whceze in the chest and } \\
\text { current use of asthma drugs? } \\
\text { Males } \\
\text { Females }\end{array}$ & $\begin{array}{l}52 \\
17 \\
35\end{array}$ & $\begin{array}{l}2.3(1.7 \text { to } 2 \cdot 9) \\
1.4(0.7 \text { to } 2 \cdot 1) \\
3.1(2 \cdot 1 \text { to } 4 \cdot 1)\end{array}$ & 0.01 & $\begin{array}{l}0.8 \\
0.5 \\
1.0\end{array}$ \\
\hline $\begin{array}{l}\text { Attacks of shortness of breath and usually } \\
\text { have wheeze in the chest? } \\
\text { Males } \\
\text { Females }\end{array}$ & $\begin{array}{l}92 \\
36 \\
56\end{array}$ & $\begin{array}{l}4.0(3.2 \text { to } 4.8) \\
3.0(2.0 \text { to } 4.0) \\
5.0(3.7 \text { to } 6.3)\end{array}$ & 0.02 & $\begin{array}{l}1 \cdot 3 \\
1.0 \\
1.7\end{array}$ \\
\hline
\end{tabular}


Table 2 Number and percentage of individuals having smoked during the observation period 1990-3 (see methods for definition)

\begin{tabular}{lllllll}
\hline & $\begin{array}{l}\text { Smokers } \\
1990\end{array}$ & $\begin{array}{l}\text { Ex-smokers } \\
1990\end{array}$ & $\begin{array}{l}\text { Smokers } \\
1993\end{array}$ & $\begin{array}{l}\text { Ex-smokers } \\
1993\end{array}$ & $\begin{array}{l}\text { Smokers } \\
1990-3\end{array}$ & $\begin{array}{l}\text { Smokers } \\
1990-3(\%)\end{array}$ \\
\hline Total & $3 \cdot 6$ & $2 \cdot 1$ & $9 \cdot 4$ & $7 \cdot 3$ & 356 & $15 \cdot 4$ \\
Males & $2 \cdot 8$ & $1 \cdot 4$ & $7 \cdot 2$ & $6 \cdot 7$ & 151 & $12 \cdot 8$ \\
Females & $4 \cdot 4$ & $2 \cdot 7$ & $11 \cdot 6$ & $7 \cdot 9$ & 205 & $18 \cdot 2$ \\
\hline
\end{tabular}

More female (18\%) than male subjects (13\%) had smoked during the observation period (table 2).

Female sex was a risk factor for incident asthma with all of the criteria tested, even when adjusted for smoking habits. The odds ratio for female subjects compared with males varied from $1.5(95 \%$ CI 1.0 to $2 \cdot 3)$ to $2.2(1.3$ to 3.7) (table 3 ). When adjusted for sex, smoking during the observation period was a significant risk factor using self reported disease, diagnosed asthma, and frequent wheezing in combination with current drug use or attacks of shortness of breath as criteria for asthma, but not when diagnosed asthma or attacks of shortness of breath were used in combination with current drug use.

In male subjects smoking was associated with a significantly increased risk of developing asthma only when defined by shortness of breath and wheezing (table 3 ). In female subjects self reported disease and combinations of symptoms, or symptoms and current asthma medication were significantly more common in smokers than in non-smokers, the odds ratio being 2.0 to 2.9 (table 3 ). However, physician diagnosed asthma and current use of asthma drugs were almost as common in non-smoking women as in those who smoked (odds ratio $1 \cdot 1)$.

The 117 individuals investigated as controls in the previous study had a marginally higher incidence than those who previously had only answered a questionnaire when self reported disease $(1.4 \%$ versus $1.2 \%)$ and physician diagnosed disease $(1.4 \%$ versus $1.0 \%)$ were used as criteria for asthma. A combination of recurrent wheezing and attacks of shortness of breath resulted in a yearly incidence of $1 \cdot 1 \%$ in controls and $1.3 \%$ in those not previously examined. Of the previously examined subjects $17 \%$ were smokers compared with $15 \%$ of those not investigated. None of the differences was statistically significant.

\section{Discussion}

A sex difference in the incidence of asthma in teenagers has been reported previously. ${ }^{3}$ In this paper we report results that confirm this difference and indicate that differences in smoking habits, and the risk associated with smoking, may partly explain the observed differences. Female sex does, however, seem to be a risk factor for developing asthma independent of exposure to tobacco smoking between the ages of 16 and 19.

This study illustrates some of the difficulties associated with studies of incidence. We started out with a total year cohort of 360016 year olds and studied the relations between a common disease and a common potential risk factor with acceptable response rates, but only found a limited number of incident cases from which to draw conclusions.

The incidence of asthma is usually studied by comparing results from repeated cross sectional questionnaire studies in a population. In the present study the question "have you ever had asthma?" was answered positively by $3 \cdot 7 \%$ of male subjects and $5.9 \%$ of female subjects who had answered the question negatively three years previously. As the design of the study included an intervention with an extensive examination and establishment of diagnoses in individuals reporting symptoms in the initial survey, this approach was not appropriate in the present study. The method used could be expected to result in a somewhat lower incidence than the comparison of two questionnaires. On the other hand, the results are likely to be more valid as individuals who actually had asthma at the time of the initial survey, but did not yet know it, were excluded.

We have chosen to exclude all subjects with past or present asthma reported in 1990, as well as the 44 individuals who reported symptoms at the initial survey who did not take part in the following examination. The reasons for the exclusion of these 44 individuals were not ob-

Table 3 Odds ratios (95\% confidence intervals) for incidence of asthma using different criteria

\begin{tabular}{|c|c|c|c|c|}
\hline Criteria for incidence of asthma & $\begin{array}{l}\text { Sex (female/male) } \\
\text { standardised for } \\
\text { smoking }\end{array}$ & $\begin{array}{l}\text { Smoking } \\
\text { (smokers/non-smokers) } \\
\text { standardised for sex }\end{array}$ & $\begin{array}{l}\text { Smoking } \\
\text { (smokers/non-smokers), } \\
\text { males }\end{array}$ & $\begin{array}{l}\text { Smoking } \\
\text { (smokers/non-smokers), } \\
\text { females }\end{array}$ \\
\hline Have you ever had asthma? & $1.6(1 \cdot 1$ to $2 \cdot 5)$ & $2 \cdot 2(1.3$ to $3 \cdot 6)$ & $1.4(0.5$ to 3.9$)$ & $2 \cdot 7(1.5$ to $4 \cdot 8)$ \\
\hline Asthma diagnosed by physician? & $1.7(1.1$ to 2.7$)$ & $1.9(1.1$ to 3.4$)$ & $1.7(0.6$ to 4.8$)$ & $2.0(1.0$ to $4 \cdot 0)$ \\
\hline $\begin{array}{l}\text { Asthma diagnosed by physician } \\
\text { and current use of asthma drugs? }\end{array}$ & $2 \cdot 2(1.3$ to 3.7$)$ & $1.0(0.5$ to 1.8$)$ & $0.8(0.2$ to 3.5$)$ & $1 \cdot 1(0.5$ to $2 \cdot 4)$ \\
\hline $\begin{array}{l}\text { Attacks of shortness of breath and } \\
\text { current use of asthma drugs? }\end{array}$ & $1.9(1.2$ to 3.0$)$ & $1.6(0.9$ to 2.6$)$ & $0.5(0.1$ to 2.0$)$ & $2 \cdot 1(1.2$ to $3 \cdot 6)$ \\
\hline $\begin{array}{l}\text { Usually have wheeze in the chest } \\
\text { and current use of asthma drugs? }\end{array}$ & $2 \cdot 1(1 \cdot 1$ to $3 \cdot 7)$ & $2 \cdot 1(1 \cdot 1$ to $3 \cdot 8)$ & $0.9(0.2$ to 4.0$)$ & $2.7(1.4$ to $5 \cdot 1)$ \\
\hline $\begin{array}{l}\text { Attacks of shortness of breath and } \\
\text { usually have wheeze in the chest? }\end{array}$ & $1.5(1.0$ to 2.3$)$ & $2 \cdot 7(1.8$ to $4 \cdot 2)$ & $2 \cdot 3(1 \cdot 1$ to $4 \cdot 7)$ & $2.9(1.7$ to 4.8$)$ \\
\hline
\end{tabular}


vious; four of them reported that they had diagnosed asthma in the second survey and three used asthma medication. As it is probable that they also had asthma in 1990 we have excluded them from from the calculations with a risk of a slight underestimation of the incidence as a result.

By definition, incidence will always be studied in a previously investigated population. The impact of the previous investigation is largely unknown but it could be expected to raise the incidence. The influence of an extensive examination 2-3 years previously in controls in the initial survey was small, however, and the influence of answering a questionnaire three years before was probably negligible.

The criteria used to define asthma have a considerable impact on the results. The definitions including self reported disease all had a high specificity, while the sensitivity was lower when validated against asthma associated symptoms and signs of bronchial lability (unpublished observations). The figures based on self reported disease reported here are therefore probably minimal values for the incidence of asthma.

The incidence rates found in this study were generally higher than those reported by Anderson et al in individuals aged 17-23 years ${ }^{3}$ and by Sherman et al in 7-23 year olds. ${ }^{7}$ The estimated incidence using recurrent wheezing and use of asthma drugs was, however, close to that reported previously, and was also close to the incidence of new drug use for asthma. The results suggest that the incidence of asthma in late adolescence is about $1 \%$, and that there is a sex difference with a higher incidence in female subjects.

The reason for the increased incidence of asthma in women is unknown. The incidence is not affected by the age at onset of menarche or puberty, indicating that hormonal factors are not the principal explanation. ${ }^{8}$ The relation between the incidence of asthma and atopic disease does not differ between the sexes and does not explain the observed differences in incidence. $^{3}$

Although parental smoking is correlated with childhood asthma9 and bronchial hyperresponsiveness is more prevalent in smokers than in non-smokers independent of $\operatorname{sex}^{10}$ (even if not always when standardised for differences in $\left.\mathrm{FEV}_{1}\right){ }^{11}$ the correlation between smoking and asthma is not clearcut in adults. ${ }^{1}$ A significantly increased risk of developing asthma has been reported in some studies for women (but not men) who smoke, ${ }^{12}$ and in others for men (but not women) who smoke. ${ }^{13}$ Neither the prevalence nor the incidence of asthma was found to be influenced by smoking habits in one large survey, ${ }^{14}$ while Dodge and Burrows found a significantly increased risk for asthma incidence among smokers. ${ }^{2}$ The increased risk found in their study may, however, reflect different diseases, especially in older age groups where chronic bronchitis or emphysema was often concomitantly diagnosed. In the present study the correlation between smoking and the incidence of asthma was indisputable. Such a correlation is probably more easily found in a young population where chronic obstructive pulmonary disease (COPD) is rare, rather than an older population in which COPD could be expected to influence the diagnoses given to smokers.

In male subjects who smoked only the criteria based on symptoms alone resulted in a signficantly increased risk for asthma compared with those who did not smoke. In female smokers, on the other hand, all criteria except physician diagnosed asthma in combination with current use of antiasthmatic drugs resulted in a higher risk. There are a number of possible explanations for these findings including: (1) a sex difference in the number of cigarettes smoked; (2) a tendency in male subjects with airway symptoms not to start smoking; (3) a tendency among males who smoke to consult a doctor less often, even when they have respiratory symptoms; and (4) a true difference between the sexes in the risk of asthma induced by smoking.

In this study we have no information on the number of cigarettes smoked, but in our previous study in which 60016 year olds were interviewed there was no sex difference in the number of cigarettes smoked. The proportion of non-smoking male subjects with airway symptoms in 1990 who had started to smoke in 1993 was somewhat higher than in those without symptoms ( $5.6 \%$ versus $3.4 \%$ ). In female subjects the "smoking incidence" did not differ between symptomatic and asymptomatic individuals. There was a moderately lower medical consultation rate for airway symptoms among male subjects who smoked during the observation period and reported attacks of shortness of breath than among those who did not smoke (33\% verus $47 \%$ ). This difference was also seen in female subjects $(37 \%$ versus $51 \%)$. None of these factors seems to explain the observed differences, however, and a true sex difference in the susceptibility to smoking seems likely.

In conclusion, there is a substantial incidence of asthma in subjects in their late teens. The incidence is higher in female than in male subjects, independent of smoking, but female subjects may have an increased risk for developing asthma if they smoke. The incidence found in this population study is close to the incidence of new drug use for asthma in the county of Jämtland, and data on the use of asthma drugs can be used to estimate the incidence of asthma. The findings emphasise the importance of campaigns to reduce tobacco smoking, particularly in young women.

This study was supported by grants from The County Council of Jämtland, The Swedish Association against Asthma and Allergy, "Förenade Liv" Mutual Group Life Insurance Company, Stockholm, Sweden, and The King Oscar II Jubilee Fund.

1 Burney PGJ. Epidemiology. In: Clark TJH, Godfrey S, Lee TH. eds. Asthma. 3rd edn. London: Chapman and Hall, 1992:254-307.

2 Dodge RR, Burrows $B$. The prevalence and incidence of asthma and asthma-like symptoms in a general population sample. Am Rev Respir Dis 1980;122:567-75.

3 Anderson HR, Pottier AC, Strachan DP. Asthma from birth to age 23: incidence and relation to prior and concurrent atopic disease. Thorax 1992;47:537-42.

4 Larsson L, Boëthius G, Uddenfeldt $M$. Differences in utilization of asthma drugs between two neighbouring Swed- 
ish provinces: relation to symptom reporting. Eur Respir f 1993;6:198-203.

5 Larsson L, Boëthius G, Uddenfeldt M. Differences in utilisation of asthma drugs between two neighbouring Swedish provinces: relation to prevalence of obstructive airway disease. Thorax 1994:49:41-9.

6 Svensk Läkemedelsstatistik (Drug sale statistics in Sweden) Apoteksbolaget Stockholm (year publication, in Swedish).

7 Sherman CB, Tosteson TD, Tager IB, Speizer FE, Weiss ST. Early childhood predictors of asthma. $A m \mathcal{F}$ Epidemiol 1990;132:83-95.

8 Anderson HR, Bland JM, Patel S, Peckham C. The natural history of asthma in childhood. $\mathcal{f}$ Epidemiol Community Health 1986;40:121-9.

9 Weitzman M, Gortmaker S, Walker DK, Sobol A. Maternal smoking and hildhood asthma. Pediatrics 1990;85:505-11. 10 Woodcock AJ, Peat JK, Salome CM, Yan K, Anderson SD,
Schoeffel RE, et al. Prevalence of bronchial hyperresponsiveness and asthma in a rural adult population. responsiveness and as

11 Rijcken B, Schouten JP, Mensinga TT, Weiss ST, De Vries $K$, Van Der Lende $R$. Factors associated with bronchial responsiveness to histamine in a population sample of adults. Am Rev Respir Dis 1993;147:1447-53.

12 Kiviloog J, Irnell L, Eklund G. The prevalence of bronchial asthma and chronic bronchitis in smokers and nonsmokers in a representative local Swedish population. Scand F Respir Dis 1974;55:262-76.

13 Vesterinen E, Karpio J, Koskenvuo M. Prospective study of asthma in relation to smoking habits among 14729 adults. Thorax 1988;43:534-9.

14 McWhorter WP, Polis MA, Kaslow RA. Occurrence, predictors and consequences of adult asthma in NHANESI and follow-up survey. Am Rev Respir Dis 1989;139:721-4. 